\title{
Educação corporativa e desenvolvimento profissional na dinâmica sócio-cultural das empresas
}

\author{
Antonia Colbari*
}

\section{Introdução}

Desvendar a matriz de saberes e valores que pavimentam os processos de formação do trabalhador sob os impactos das mudanças no universo produtivo e no mercado de trabalho tem sido um grande desafio. ${ }^{1}$ Suscita várias indagações, entre elas a de como as ações de qualificação e de treinamento implementadas em unidades empresariais - a educação corporativa - integram-se na dinâmica sócio-cultural e no referencial simbólico das organiza-

* Doutora em Sociologia/Iuperj; Professora da Ufes; Pesquisadora do CNPq. Autora dos livros Rumos do movimento sindical no Espírito Santo. Vitória: Edufes/ Florecultura, 2003; Bancários: 60 anos de historia. Vitória: Publiq/Seebes, 1995; Ética do Trabalho: a vida familiar na construção da identidade profissional. São Paulo: Letras\&Letras/Edufes, 1995. E-mail: alcolbari@terra.com.br

1 Projeto desenvolvido com apoio institucional do CNPq e com a participação de Carla Rosa Soares, bolsista de IC/CNPq e aluna do curso de Ciências Sociais da Ufes. A primeira versão deste artigo foi publicada nos Anais do V Workshop Empresas, Empresários e Sociedade, Pucrs, Porto Alegre, 2006.

\begin{tabular}{|l|l|l|l|l|l|}
\hline Civitas & Porto Alegre & v. 7 & n. 1 & jan.-jun. 2007 & p. 9-34 \\
\hline
\end{tabular}


ções. Dois objetivos conduziram o percurso analítico deste artigo: compreender a teia de significados, valores e representações que embasam essas ações de qualificação e de treinamento, e explorar as ambigüidades que permeiam os processos formativos dirigidos aos trabalhadores da área operacional e aos vinculados à gestão.

O universo empírico desta análise é formado por três grandes empresas localizadas no estado do Espírito Santo, sobre as quais existe significativa base de dados acumulados por meio de pesquisas anteriormente realizadas. Esta base de dados foi complementada com a coleta de informações em documentos e relatórios divulgados pela Internet, e por meio de contato direto com integrantes do setor de Recursos Humanos, o que permitiu organizar um quadro de referências empíricas a partir das quais foi possível explorar algumas hipóteses de trabalho.

Apesar das possibilidades de vários recortes analíticos, priorizou-se a análise do discurso das empresas sobre seus objetivos, valores, e sobre a qualificação profissional. Veiculados por meio dos documentos corporativos, estes discursos apresentam-se moldurados pelos conteúdos da literatura especializada no mundo dos negócios, cujo propósito é difundir modelos normativos a serem aplicados na gestão e na formação de pessoas. Disseminam informações, sobretudo em relação às inovações, mas também carregam uma bagagem normativa e ideológica repassando instruções práticas recheadas de conteúdo moral, altamente prescritivo.

Trata-se de conteúdos retóricos instigantes em função de sua propriedade de revelar, mas também de dissimular, práticas e representações relevantes para compreensão das dinâmicas empresariais, sobretudo no que concerne às suas dimensões culturais e simbólicas. Como peças de uma construção ideológica, estes discursos têm, em princípio, a capacidade de se infiltrar no conjunto das representações típicas da época, inclusive nos discursos dos sindicatos de trabalhadores; fornecem um repertório de símbolos, representações legítimas e esquemas de pensamento que modelam as práticas discursivas, impregnando a visão de mundo dos atores, a opinião pública e as explicações científicas. São, portanto, construções ideológicas na acepção de Dumont (1992), não importando se verdadeiras ou falsas mas, sim, a sua proximidade com a experiência moral da vida cotidiana, o que revela a sua propriedade de 
alimentar a imaginação e de propor modelos para a orientação das ações das pessoas (Boltanski e Chiapello, 1999).

\section{Educação e cultura corporativa: enquadramento teórico}

Escapa aos propósitos deste estudo explorar o amplo debate sobre qualificação profissional que atravessa vários campos disciplinares. No enquadramento da Sociologia do Trabalho, a qualificação do trabalho tem sido analisada sob várias perspectivas: na ótica da divisão do trabalho, relacionada às funções de coordenação, controle, poder e dominação; no ângulo da cultura organizacional, com ênfase nos processos adaptativos e integrativos; na dimensão estratégica, delimitada pelas relações de poder entre capital e trabalho; em termos de mercado de trabalho e do universo dos ofícios e das profissões, com ênfase no posto de trabalho e no difuso conceito de cultura (Segrestin, 1997; Sainsaulieu, 1977; Dubar, 1998; Supervielle e Quiñones, 2003).

Uma das modalidades de qualificação profissional é a chamada educação corporativa que envolve um espectro ampliado de variáveis e aciona diversos campos disciplinares. Sob esta denominação, está mais presente no campo das ciências da Administração, com destaque na sua propriedade de ferramenta de gestão do trabalho e das organizações. Cabe lembrar a distinção entre educação corporativa, cujo objetivo é desencadear processos de aprendizagem focados nas competências demandadas pela empresa, e educação empreendedora, cujo foco é estimular o empreendedorismo, preparar as pessoas para criarem e desenvolverem oportunidades de negócio (Garavan e O’Cinneide, 1994).

Neste ensaio, o enquadramento teórico estará delimitado por conceitos desenvolvidos na vertente da sociologia econômica, que captura a empresa como instituição inscrita em um contexto cultural e sociopolítico mais abrangente, portanto a define como algo mais do que um mero espaço de troca de mercadorias, de relações estritamente mercantis. Essa trilha teórica tem história no campo da Sociologia pois, à luz do repertório clássico da disciplina, a configuração de uma empresa não se pauta exclusivamente pela lógica do mercado, uma vez que, se assim fosse, criaria somente vínculos fortuitos, inconsistentes e efêmeros, e produziria apenas uma "solidariedade precária", 
firmada na "relação social mercantil superficial, conflitual e instável" (RaudMattedi, 2005) que não garantiria a continuidade de uma relação contratual. Daí a necessidade da existência de instituições alicerçadas nos costumes mentais e comportamentos enraizados nas regras jurídicas (Durkheim, 1999).

Por sua vez, as categorias analíticas weberianas descortinam outro ângulo da vida organizacional, a saber, a empresa como espaço de duas formas básicas de interação social: troca entre parceiros e concorrentes, e competição entre clientes e vendedores. À visão econômica do poder, agrega-se a política, a dimensão de luta e poder. A troca pressupõe uma situação de equilíbrio construída em um campo de conflito entre interesses materiais e morais opostos, condicionados pelas visões do mundo e legitimados pelos valores da sociedade (Weber, 1991), portanto, social e historicamente situados.

A dinâmica das empresas não exclui as relações de poder existentes entre os atores econômicos, os interesses opostos entre patrões e empregados. Todavia, diante de concorrentes externos, esses atores antagônicos no espaço intra-organizacional convertem-se em atores cooperativos. A bandeira da competitividade, questão crucial para a sobrevivência das empresas, tem favorecido a minimização do conflito de interesses específicos em prol de interesses dos atores - a lucratividade, para uns, e os empregos, para outros.

Em suma: a relação patrão e empregado, as demandas de qualificação profissional e as representações sobre o trabalho e a empresa não se esgotam em seu enquadramento na dimensão mercantil. A coesão social no interior das organizações é produzida pelos padrões de solidariedade (no sentido durkheimiano) e de sociabilidade, e pelas formas de legitimação de interesses. A dimensão socializadora é crucial para garantir a permanência do processo de troca, de interação, ou seja: as relações de cooperação que têm lugar no universo micro social das empresas. Essa dimensão socializadora, que produz a coesão social, não surge espontaneamente da racionalidade embutida no jogo de interesses, como também não se esgota no ato da troca; depende da presença de certas condições, de regras formais e informais e de referências morais e simbólicas - as dimensões culturais e simbólicas das organizações ou a cultura organizacional - que sustentam as micronegociações atualizadas permanentemente, garantindo, desta forma, a continuidade e a previsibilidade da cooperação. 
Porém, a adaptação das organizações ao ambiente externo e a manutenção da coesão no plano interno não dependem apenas da transmissão da cultura da organização aos seus integrantes; é preciso colocá-la em prática a serviço da competitividade, por meio da mobilização de recursos diversos, como quadros qualificados, reuniões de trabalho, estudos prévios e programas especializados (Schein, 1984, apud Hirose, 2000). Não é por outra razão que a noção de cultura corporativa se confunde com a visão dos dirigentes a respeito da organização (Hirose, 2000).

Apesar desta visão "oficial" de cultura, as empresas estão submetidas a uma matriz diferenciada de valores e interesses, pois abrigam, no seu interior, diversas culturas profissionais e diversos grupos de status. Assim, a construção de uma identidade coletiva e de um consenso em torno dos objetivos estratégicos e da missão da empresa depende da capacidade de definir um “quadro de referências básicas" que sirva como princípio orientador na gestão das divergências, dos conflitos e das resistências (Sainsaulieu, 1977). E mais: além das pressões inerentes à dinâmica intra-organizacional, as empresas estão inseridas na cultura de uma sociedade, nas tradições e nas instituições locais (Cappellin e Giuliani, 2002), portanto, são heterônomas, submetidas a várias instâncias regulatórias, como instituições governamentais, sindicais e educacionais.

Se, na condição de ator econômico, as empresas orientam suas ações e comportamentos para o mercado, perseguindo a maximização dos lucros e a competitividade, o mesmo não ocorre em relação ao seu aparato social e político, no qual se encaixa a política de recursos humanos. Inseridas em uma teia social mais ampla, as empresas estão submetidas a tensões entre lógicas não reduzidas a um único princípio; vivem sob o imperativo da competitividade, o que as coloca em uma situação de dependência do desempenho das equipes. Ou seja, para garantir esse desempenho, estão obrigadas a motivar a cooperação entre seus integrantes (Villavicencio, 2000) e investir nos processos sociais de qualificação e de aprendizagem. Além disso, também respondem às demandas mais gerais provenientes de ambientes externos, em particular das referências valorativas predominantes nas sociedades, expressas nas exigências de caráter ético, político, social e ambiental.

Esta argumentação, que rechaça a concepção da empresa apenas sob ângulo da lógica mercantil, se estende também à natureza dos mercados de 
trabalho, da relação que nele se estabelece entre status e contrato. Hyman (2005), seguindo a trilha de Polanyi (1980) e Offe (1976), problematiza a tensão entre a construção econômica do mercado de trabalho e os constrangimentos sociais determinados pelas especificidades nacionais. Assim, para o autor, pode ser identificada uma variedade de estruturas institucionais que pautam a relação empregador/empregado. Essas instituições "civilizadoras" modelam o mercado de trabalho, fazendo com que ele não seja um genuíno espaço de compra e venda de mercadorias.

Considerações como estas já antecipam uma série de questões que envolvem os processos formativos direcionados ao mercado de trabalho, incluindo-se neste universo uma modalidade específica de formação e treinamento: a educação corporativa.

A compreensão do sentido da educação corporativa está permeada por dualismos, polarizações, alimentando a necessidade de conciliar formas de solidariedades diferenciadas e ambíguas, mas complementares. Por um lado, a inserção em uma matriz comunitarista reforça a identificação e o envolvimento com os valores e a missão da empresa; estimula a cooperação entre os integrantes das equipes e a legitimidade das lideranças emergentes do próprio grupo, mas sem perder de vista os imperativos do mercado. Neste eixo, a função integradora e socializadora impõe os valores e a cultura da empresa aos seus integrantes. O foco do aprendizado nas ações de treinamento e de qualificação deve ser a organização, fortalecendo a cultura corporativa.

Por outro, a inserção na matriz contratualista favorece o destaque dos saberes técnicos, o autodesenvolvimento, as competências organizacionais e o plano estratégico de negócios; aciona a diferenciação e a individualização, sem, no entanto, dissociá-las da base de valores e de símbolos culturais - a identidade da empresa. Neste eixo, sobressai o foco individualizante representado pelo plano de autodesenvolvimento profissional que, apesar da marca do indivíduo, não descarta as razões da empresa, afinal o plano de cada um deve estar em sintonia com as demandas da organização.

Em suma: o mercado é imperativo, mas o ajustamento a suas exigências pressupõe uma engenharia social mais complexa que ativa os interesses individuais, porém acoplados aos interesses corporativos; estimula a iniciativa individual, mas sem subestimar a importância da cooperação e do trabalho em equipe; exalta as relações profissionais e a visão da empresa como insti- 
tuição do mercado, mas sem prescindir de um padrão de relação social de índole comunitária. Assim, as dimensões socializadoras, integradoras e racionalizadoras embutidas nos processos formativos estão associadas à duplicidade que marca as representações da empresa: instituição do mercado, portanto sujeita à lógica mercantil, e instituição comunitária. $\mathrm{O}$ contrato é, por excelência, o fiador das relações sociais, mas não elimina a regulação oriunda dos sistemas de valores e das crenças que sustentam as posições de status.

\section{A educação corporativa: conhecimento e inovação}

A defesa, quase apologética, que diferentes setores da sociedade atual fazem da educação, como uma espécie de panacéia para todos os males, aparece, no universo cultural corporativo, na postura de investimento em um processo formativo de caráter contínuo, permanente, dirigido a todos os trabalhadores da empresa. A difusão da educação corporativa é contemporânea das mudanças ocorridas no ambiente de negócios, provocadas pelo aumento da competitividade empresarial que, ao valorizar o conhecimento, destaca também a gestão do conhecimento. Assim, a abordagem da educação corporativa, sobretudo no campo da Administração, aparece associada a questões como: a importância crescente da geração de conhecimento, a valorização do capital intelectual e a ênfase na aprendizagem organizacional que popularizou a expressão learning organization (Meister, 1999; Drucker, 1993; Alperstedt, 2001).

A concepção de organização que aprende e de gestão do capital intelectual insere a educação corporativa no sistema de gestão de pessoas, como forma de alinhar o desenvolvimento dos talentos humanos e as estratégias empresariais, as competências organizacionais, a "missão" e os valores da empresa.

A construção do discurso da qualificação profissional não se faz apenas colada no atendimento das necessidades técnicas, operacionais e logísticas, inerentes ao desempenho das funções, mas também na ótica da socialização dos trabalhadores, de sua inserção no universo cultural das organizações. Para atingir os seus propósitos, as organizações não podem negligenciar esforços no sentido de disseminar e consolidar valores, normas, princípios e missão, atingindo a totalidade de seu pessoal, independente das funções, do 
nível salarial e da posição na hierarquia de poder. Uma exigência ainda mais desafiadora diante das mudanças no universo produtivo que, entre outras alterações, tende a "desmaterializar" o trabalho e transformar o conhecimento em instrumento para a concorrência nos mercados. Mas não basta a aquisição de conhecimento técnico e instrumental. As mudanças recentes levam as empresas a implantarem sistemas educacionais que privilegiem o desenvolvimento de atitudes, posturas e habilidades. Demanda-se um trabalhador que, além das competências técnicas, apresente outras qualidades como independência, autonomia, criatividade, capacidade de comunicação e de iniciativa. Este perfil profissional flexível e inventivo, ancorado em conhecimento e refinamento das competências redefine os padrões disciplinares e socializadores vigentes, valorizando as estratégias mobilizadoras e persuasivas.

Ilustra este processo o caso francês, relatado por Boltanski e Chiapello, no qual a expressão cadre, em geral associada à rigidez burocrática e à racionalidade calculista, tende a ser substituída por manager (Boltanski e Chiapello, 1999, p. 121), termo mais apropriado para designar os animadores de equipe, catalisadores, coachs, visionários. Ao contrário dos cadres, os managers são intuitivos, humanistas, visionários, generalistas, criativos, flexíveis, inclusive para se deslocarem em espaços geográficos e culturais diferentes (Boltanski e Chiapello, 1999, p. 123).

Também para Souza (2005, p. 5), a ênfase na capacidade de criar e de inovar acaba por redefinir os perfis de gestão, pois cresce a dependência das empresas em relação aos "líderes capazes de articular com autonomia e flexibilidade seus próprios valores" e de convertê-los em iniciativas inovadoras para a organização. O indivíduo empreendedor é uma "espécie de líder estratégico integrador das políticas humanísticas à gestão estratégica", a quem cabe promover o comprometimento dos colegas com a organização (Souza, 2005, p. 8). Competências especiais são necessárias para se lidar com a complexidade das atividades cotidianas, tendo em vista garantir a obtenção dos objetivos estratégicos da empresa e os padrões de qualidade esperados, bem como assegurar que todos os membros da empresa incorporem compromissos de responsabilidade social, éticos e ecológicos. Neste contexto, as tradicionais relações entre chefes e subordinados cedem espaço às equipes de colaboradores, portadoras de um líder cuja ação de controle está referenciada muito mais por elementos simbólicos e subjetivos do que pelos constrangimentos 
disciplinares mais objetivos e externos ao grupo (Offe, 1976; Pagès et al., 1987; Boltanski e Chiapello, 1999).

Se o empreendedor corporativo é menos original do que o tipo individualista schumpeteriano, ele tem que ser mais cooperativo, a fim de ser bem sucedido nos seus esforços de transformar uma empresa tradicional em uma unidade empreendedora; de obter a adesão dos subordinados aos interesses da empresa, mobilizando-os para assumirem posturas inovadoras. As empresas pesquisadas incorporam uma cultura de inovação, esta vista como valor que faz parte da missão e dos valores da empresa. A inovação tem a ver com o talento e a criatividade individual, que podem ser ativados, exercitados e sustentados no universo microssocial das organizações que, por sua vez, permanece conectado aos arranjos estruturais e sociais no nível macrossocial (Kanter, 2000).

A educação corporativa difere, segundo Éboli (2005), do sistema tradicional de treinamento por ser concebida a partir do plano estratégico dos negócios. Abrange as ações das empresas dirigidas à qualificação e ao treinamento de pessoal em todos os níveis da organização. Cabe a ela criar um

ambiente e uma cultura empresarial cujos princípios e valores disseminados sejam propícios para processos de aprendizagem ativa e contínua, que favoreçam a formação e a atuação de lideranças exemplares e educadoras que aceitem, vivenciem e pratiquem a cultura empresarial e, assim, despertem e estimulem nas pessoas as posturas do autodesenvolvimento (Éboli, 2005, p. 120).

O investimento em processos formativos de forma contínua e permanente é considerado um requisito indispensável na busca pela competitividade no mercado. E, como se trata de um processo permanente, um de seus desdobramentos é a diluição da separação entre tempo e espaço de trabalho e tempo e espaço de aprendizagem, o que significa, na visão de Éboli (2004), converter o trabalhador em "eterno aprendiz", seja de maneira sistematizada, seja na experiência cotidiana do trabalho e da vida em geral.

No entanto, se, no plano da retórica, as possibilidades de desenvolvimento profissional, em particular das capacidades inovadoras e empreendedoras, devem ser estendidas a todos os funcionários, na prática, o seu foco prioriza as pessoas na área de gestão e em funções de alta complexidade tecnológica. 
Verifica-se que, nesta investida empresarial nas atividades de formação, a implementação de ações formais de capacitação e o incentivo à aprendizagem na situação de trabalho precisam levar em conta a carência ou baixa qualidade da escolarização básica, e as deficiências da formação técnica dos egressos no mercado de trabalho (Eboli, 2004). Explica-se, desta forma, a razão do maciço investimento das empresas em escolaridade básica, bem como a obrigatoriedade do nível médio com requisito de ingresso.

Este investimento em complementação da escolaridade básica não significa reduzir o papel da educação corporativa ao esforço de compensar as carências do sistema oficial de ensino. Ela tem um status próprio, integra o sistema de gestão de recursos humanos e influencia a modelagem de uma concepção de empresa como espaço de aprendizagem. A passagem de uma empresa que treina para uma organização de aprendizagem envolve mudanças significativas na gestão e nas ações de formação. Se não há dúvidas quanto ao fato de ser o espaço de trabalho um espaço de controle (que se desenrola em uma organização de controle), também é cada vez mais evidente a sua configuração como espaço de aprendizagem. Nas organizações de aprendizagem, ganham destaque os formadores internos - os responsáveis por um tipo de aprendizagem seletiva, útil à empresa, "supervisonada" ou vinculada ao setor de recursos humanos. O "coach" é um exemplo desse agente de aprendizagem, ao realizar o acompanhamento personalizado tendo em vista desenvolver o potencial individual de cada um.

Pesquisas realizadas em indústrias de bens intermediários evidenciaram que a importância da escolaridade não abalou a posição do local de trabalho como instância decisiva para a qualificação dos operadores (Fartes, 2002). Se, no contexto da "sociedade do conhecimento" (Drucker, 1993), aprendizagem e qualificação são processos contínuos, permanentes, o desafio é mapear a educação no sentido de captar, na vivência do cotidiano do trabalho, as interações entre os saberes formais e os conhecimentos tácitos.

A educação corporativa não se organiza independente da complexidade dos processos que definem a aquisição da qualificação. A trajetória de vida familiar e profissional, as experiências de vida, os conhecimentos tácitos interagem com os conhecimentos formais, em contextos em que a dinâmica das mudanças tecnológicas e as modalidades de gestão e organização do trabalho modelam a gestão da aprendizagem no local de trabalho, estimulan- 
do ou bloqueando o reconhecimento da experiência e da vivência no desempenho profissional (Fartes, 2002).

O investimento em formação de pessoal assume várias formas, sendo uma das mais elaboradas o projeto de uma Universidade Corporativa (UC) que, a despeito de seu estatuto conceitual e teórico pouco consistente, não deixa de ser uma modalidade mais abrangente e sistematizada de educação estrategicamente centralizada e dirigida a todos os integrantes de uma empresa e à cadeia de valor (Eboli, 2005; Meister, 1999).

A concepção de uma universidade corporativa marca o status atual da educação corporativa, em particular nas grandes empresas. Vinculadas às estratégias de gestão de recursos humanos implementadas, as UCs tratam a aprendizagem como um valor e como uma prática de caráter intensivo, integrado, permanente e compartilhado (envolve todos os níveis hierárquicos e se estende aos parceiros estratégicos em toda a cadeia produtiva do negócio); incorporam uma visão mais ampla e complexa da empresa, fato que, de um lado, favorece uma postura pró-ativa diante do conhecimento, ancorada na percepção antecipada das necessidades estratégicas do negócio e, de outro, o fortalecimento da cultura corporativa (Meister, 1999; Alperstedt, 2001; Dengo, 2001; Brandão, 2004; 2006). Avança em direção à crescente racionalidade na formação, pois além de reduzir custos e aumentar a eficiência, alinha as ações de formação, atualização e desenvolvimento contínuo das pessoas com as reais necessidades da empresa.

A simbologia da expressão "universidade" e a ênfase na imagem institucional imposta aos seus programas permitem leituras diversas: abuso de linguagem, estratégia mercadológica, modismo, crítica ao ensino tradicional e seu distanciamento da realidade, ou modalidade avançada de educação corporativa em sintonia com a gestão de pessoas e alinhada com as competências e os objetivos organizacionais (Brandão, 2004; 2006). Esta vocação das UCs não significa, no entanto, o seu insulamento, pois elas se abrem ao universo mais abrangente das instituições de ensino superior (IES). No âmbito dos cursos de capacitação gerencial, em nível de graduação e de pós-graduação, a tendência é de estreitar as parcerias com as instituições de ensino superior tradicionais (Alpersdetd, 2001). Mesmo com a ressalva destas parcerias, a existência das UCs explicita uma tendência na contramão da terceirização, a saber: as empresas assumem a gestão de um tipo especial de unidade educa- 
cional, algo, por natureza, estranho à sua vocação específica. Assim, permanece a ambigüidade da situação: a parceria com as IES externaliza a formação que, por sua vez, aparece internalizada na concepção de UCs, em nome da necessidade de desenvolver o conhecimento no interior da empresa, assegurar o processo contínuo de aprendizagem e incentivar o aprender associado ao fazer.

Entre os princípios e práticas que norteiam a educação corporativa, Éboli (2005) destaca alguns como a competitividade, perpetuidade e sustentabilidade, que se alinham aos interesses estritamente empresariais de manter e ampliar a posição no mercado. A educação é vista como forma de maximizar o capital intelectual dos trabalhadores e dos gestores, desenvolvendo competências humanas e corporativas, o que a torna um fator diferencial na competição empresarial, bem como uma estratégia de transmissão da cultura empresarial e da sustentabilidade do negócio. Outros três princípios (conectividade, disponibilidade e parceria) referem-se aos mecanismos mediante os quais a educação e o conhecimento podem potencializar a realização das metas e dos valores da empresa. Por último, o princípio da cidadania, que propõe a formação de cidadãos com capacidade de refletir criticamente sobre a realidade organizacional e de transformá-la, superando os interesses estritamente empresariais.

Esses princípios reiteram a dimensão socializadora da qualificação profissional. A sobrevivência e solidez das organizações não dependem apenas das condições econômicas, financeiras e tecnológicas, mas também de sua capacidade de disseminar e consolidar seus valores e princípios básicos. Como as culturas corporativas são permeáveis, valores, normas, princípios e missão precisam atingir todas as pessoas no interior de um universo organizacional, independente das funções, do nível salarial e da posição na hierarquia de poder.

À luz desses princípios, a Educação Corporativa explicita tanto o padrão de solidariedade fundado na matriz comunitária (cooperação, identificação e envolvimento com os valores e a missão das empresas), como, também, o padrão de solidariedade fundado na matriz contratualista (saberes técnicos, autodesenvolvimento, competências organizacionais, diferenciação e individualização). 
O princípio da conectividade merece um comentário mais extenso, pois reforça o caráter de construção social do conhecimento organizacional, pressupondo, desta forma, a existência de mecanismos de gestão que favoreçam uma margem maior de liberdade no processo de comunicação e de interação (Habermas, 1987), tornando possível o compartilhamento de conhecimento e a troca de experiência. Se esse aspecto justifica o investimento na interação, valorizando o coletivo, aos analistas ele coloca o desafio de decifrar uma situação paradoxal: como conciliar este caráter de construção social do conhecimento com as tendências individualistas, apontadas nas organizações contemporâneas pela literatura versada no processo e nas relações de trabalho.

Trata-se de um paradoxo real, criado pela forma como os processos intra-organizacionais são compreendidos a partir de quadros teóricos delineados em campos disciplinares diversos, sobretudo na sócioantropologia do trabalho e nas ciências das organizações. As elaborações teóricas a respeito do caráter social da produção da cultura de aprendizagem ou da concepção de organização de aprendizagem apontam um fato muito relevante na dinâmica empresarial contemporânea: o conhecimento em si não é suficiente para assegurar a competitividade da empresa, sendo necessária uma cultura de colaboração, de envolvimento das pessoas na organização, de aquisição, desenvolvimento de conhecimentos e competência por meio do trabalho em equipe, como “método para escapar do 'não-treinamento' e das ciladas do desperdício de treinamento" (Jones, 1996 apud Ruas, 2005). A equipe facilita a motivação e a aprendizagem tornando-se fonte de qualidade, inovação, etc. E, neste viés, o repertório da matriz contratualista é insuficiente, marcando a relevância da matriz comunitária. À empresa, concebida na ótica de uma comunidade de aprendizagem organizacional, torna-se imperativo o recurso ao sistema cultural de significados e aos mapas cognitivos que facilitam o esforço de "construir seu conhecimento a partir de sua memória coletiva organizacional, mediante adaptações progressivas de novas idéias ou propostas, partilhando os pressupostos e o intercâmbio de experiências" (Girod, 1995 apud Ruas, 2005, p. 21). 


\section{Ações de qualificação: competências e valores}

No universo empírico desta pesquisa, com exceção de uma (a empresa C), as demais foram fundadas na década de 1970, portanto não acumularam o que Gramsci (1984) chamaria de sedimentações passivas - o peso da tradição, a herança do passado - que dificultariam a implementação das mudanças embutidas no processo de reestruturação produtiva. Tratando-se de empresas voltadas para o mercado externo, submetidas diretamente aos imperativos da competição internacional, a modernização tecnológica e gerencial é assumida como requisito vital à sobrevivência e ampliação de espaços neste cenário.

O discurso a respeito da formação profissional é uma peça de um empreendimento mais amplo que inclui as representações construídas sobre a missão, os objetivos e os valores das empresas. Extraídos dos documentos corporativos, um conjunto de expressões ou frases resume os objetivos arrojados dessas empresas, que projetam uma imagem destemida, de agressividade e de ambição frente ao mercado mundial. Buscam ser a melhor, a líder do setor; estão no topo, mas querem mais; aspiram à expansão contínua ou "evolução contínua". São também sugestivas as seguintes peças retóricas: "retorno excelente aos acionistas"; "satisfazer à demanda do mercado global"; "excelência nos padrões operacionais e nos resultados"; "perseguir uma posição cada vez mais destacada entre os melhores produtores globais"; "criar oportunidades de desenvolvimento para nossos funcionários"; "ampliar a liderança", "conquistar novos mercados"; "garantir e ampliar a própria competitividade bem como a de seus clientes".

$\mathrm{Na}$ empresa $\mathrm{A}$, os valores destacados nos documentos corporativos são: ser uma empresa "cidadã" (respeito à lei, às comunidades, ao meio ambiente, aos clientes, empregados e fornecedores); "inovadora" (oferecer no mercado produtos e serviços que somam valor para os clientes, pelo uso da tecnologia); "ética" (valorizar a vida, a liberdade e a responsabilidade individual, integridade pessoal, honestidade intelectual, a transparência nas relações, e a compreensão e o exercício do princípio da cidadania); e "profissional" (valorizar a conquista de resultados; buscar a excelência e qualidade em todas as atividades que somam valor; acreditar na iniciativa individual, no trabalho de equipe, em competência, no trabalho árduo e na meritocracia). 
A empresa B destaca os seguintes valores em seus documentos: "competência" (busca níveis de conhecimento cada vez maiores); "satisfação" (trabalha com orgulho e prazer); "desempenho" (promove resultados que atendam e superem as expectativas dos empregados, clientes e acionistas); "cidadania" (contribui para o desenvolvimento auto-sustentável da sociedade); "participação" (cultiva o trabalho em equipe e o respeito às opiniões, favorecendo a criatividade e a iniciativa); "disciplina” (cumpre normas e padrões que garantam a estabilidade dos processos, a segurança do homem e o respeito ao meio ambiente); "comprometimento" (cultiva a lealdade e integra ações que priorizem os objetivos globais da empresa).

Ética, transparência e cidadania, responsabilidade social e desenvolvimento sustentável, inovação e competência aparecem como valores a serem cultivados por todos. Não apenas em decorrência de convicções, mas porque integram a base valorativa de incontestável relevância para se atingir a metas programadas. Agir incorporando os valores faz parte da racionalidade com relação aos fins: a ação racional com relação a valores é uma forma de realizar a racionalidade instrumental. Estrategicamente, todas as decisões devem confluir para a obtenção dos resultados que, no entanto, não podem ser alcançados apenas na dureza da lógica mercantil, dissociados de uma matriz de valores, de significados que sustentam os compromissos sociais e morais. $\mathrm{O}$ comprometimento coletivo como os valores e a missão exigem processos socializadores mais refinados que vão além do treinamento em tarefas específicas. Os processos formativos são concebidos a partir dos objetivos estratégicos das empresas, associados à gestão do conhecimento e da aprendizagem organizacional.

Os valores e a missão associados às empresas contribuem para a construção de representações positivas e de uma identidade social legítima. As empresas analisadas neste artigo constituem casos típicos de sedimentação de uma imagem positiva na comunidade interna e na comunidade externa, graças às ações sociais dirigidas aos dois setores. Ao público interno, destacamse a cesta de benefícios que abrange o trabalhador e sua família, o investimento contínuo na formação e na qualificação, e a política de remuneração que, além do salário mais elevado do que a média estadual, inclui a participação nos resultados, abonos e prêmios. O pacote de ações dirigidas à comunidade é amplo e diverso, priorizando investimentos em projetos na área de educação, cultura e de meio ambiente. São iniciativas que sinalizam uma 
forte investida com o intuito de marcar a supremacia no campo simbólico, mediante a representação da empresa como uma comunidade de interesses e de valores.

É notório, no caso das empresas analisadas, o esforço bem sucedido em construir uma imagem que vai além do mercado. Desde a fundação estiveram inseridas em projetos de desenvolvimento nacional e, atualmente, são as âncoras do desenvolvimento do estado do Espírito Santo. Em fase de expansão de seus negócios participam do Plano Emergencial de Qualificação Técnico Profissional, uma parceria entre o governo estadual e o setor privado, cujo objetivo é a capacitação técnica dos jovens para suprir as necessidades de mão-de-obra.

Se as parcerias na implementação de políticas públicas no campo educacional atendem aos próprios interesses das empresas em fase de expansão, elas não estão dissociadas de outras intenções enraizadas no campo simbólico. Novamente cabe retomar Boltanski e Chiapello (1999) na sustentação da tese de que tanto a mobilização (supostamente mais isenta de manipulação do que a motivação) quanto o engajamento do indivíduo não dependem apenas de benefícios materiais; é necessário difundir a imagem de uma empresa como instituição importante para a sociedade, portanto, não preocupada apenas em maximizar os lucros. É necessário produzir um sentido para a sua existência que transcenda a produção de aço, celulose, minério de ferro, etc. Para os seus "recursos humanos", "colaboradores" em linguagem mais atual, a empresa deve ser um espaço de construção de sentido e de objetivos compartilhados, onde cada um pode exercer sua autonomia, realizar seus propósitos pessoais, mas também contribuir para o projeto coletivo. O estímulo ao engajamento dos funcionários em trabalho voluntário é uma peça desta retórica de compromisso social e de preocupação com os bens coletivos.

As três empresas têm uma trajetória comum, pois surgiram em momentos cruciais da industrialização brasileira, em que a intervenção do Estado nas atividades econômicas era parte de um projeto desenvolvimentista que incluía o incentivo à produção de bens intermediários. Outro ponto em comum entre elas é a inserção estratégica no projeto de desenvolvimento do estado do Espírito Santo que se impôs na década de 1970. Elas vivenciaram a fase de empresa estatal, fato que modelava seu padrão de gestão e seus referenciais culturais e simbólicos, enfrentaram o processo de privatização, e, mais recen- 
temente, se inseriram efetivamente nas políticas públicas e no desenvolvimento do estado e, por meio da terceirização, reforçaram a integração com médias e pequenas empresas locais.

Após a privatização, um dos desafios foi o da redefinição das competências organizacionais e das competências profissionais, que impôs a necessidade de se implementar ações de elevação da escolaridade, tornando obrigatório o ensino médio completo e de reforço da formação técnica. Outros aspectos comuns entre as empresas são a adoção do programa de autodesenvolvimento e a extensão das ações de escolarização, qualificação e treinamento a empregados das prestadoras de serviço.

A empresa A investiu na renovação tecnológica e organizativa, o que promoveu a redefinição das funções de seus funcionários, acoplada ao Programa de Gestão de Recursos Humanos, tornando necessário o desenvolvimento das habilidades cognitivas. $\mathrm{Na}$ empresa $\mathrm{B}$, as mudanças na empresa, sobretudo com a privatização, foram responsáveis pela alteração no perfil do pessoal empregado, destacando-se a preocupação em elevar seu nível intelectual e cultural, visando, principalmente, criar e consolidar uma cultura empresarial própria que afirmasse a identidade de empresa privada. Na empresa $\mathrm{C}$, como revelou a análise dos documentos corporativos, a estrutura de competências que fundamenta os processos formativos norteia-se pelos quatro pilares estratégicos da empresa: "excelência em gestão, atuação global, capacidade empreendedora e responsabilidade social e ambiental". Esses pilares estratégicos representam as competências empresariais e sustentam a imagem da empresa frente a seus clientes e acionistas e definem o diferencial competitivo da empresa no mercado. São eles os parâmetros a partir dos quais se elege o conjunto de conhecimentos, habilidades e atitudes - as organizacionais e as técnicas - que os empregados precisam desenvolver para desempenhar com excelência as suas atividades e, desta forma, assegurar os níveis de produtividade e de lucratividade almejados. Por sua vez, o mapa de objetivos e competências demandadas orienta a avaliação do perfil do funcionário e fundamenta o plano de desenvolvimento de cada um.

$\mathrm{Na}$ empresa $\mathrm{C}$, a implantação de uma universidade corporativa implementa ações cujo principal objetivo é consolidar uma cultura de desenvolvimento de pessoas que contribua para viabilizar a estratégia de crescimento e de internacionalização dos negócios. Os programas da UC são elaborados e 
implementados com vistas a dar suporte às competências organizacionais e técnicas definidas estrategicamente para os diversos perfis funcionais. São organizados em cinco unidades que atendem à diversidade de públicos e de interesses específicos de desenvolvimento, mas sempre em sintonia com as diretrizes da empresa: educação básica e profissional; qualificação profissional; gestão e liderança; cidadania corporativa; inovação em educação.

Essas considerações sobre a educação corporativa trazem à tona algumas questões clássicas nos estudos sobre a dinâmica das empresas e das relações de trabalho. Uma delas é a questão da socialização empresarial, que será abordada a seguir.

\section{A dimensão socializadora da empresa}

A análise dos discursos das empresas apontou caminhos interessantes aos propósitos de rastrear as dimensões culturais, valorativas e simbólicas das empresas, difundidas ou embutidas nos programas de qualificação e nos sistemas de recursos humanos. Como espaço social culturalmente modelado, as empresas não podem ser negligentes em relação aos processos socializadores de seu pessoal, dos quais os programas de qualificação e de treinamento constituem-se em peça modelar. Por sua vez, se a qualificação é uma construção social, um dos desafios analíticos situa-se nessa conjunção entre saberes técnicos, competências organizacionais e a base de valores, de símbolos culturais. Como as culturas corporativas são permeáveis, seus valores, normas, princípios e missão precisam atingir a totalidade de seu pessoal, independentemente das funções, do nível salarial e da posição na hierarquia de poder.

As estratégias de formação profissional das empresas integram o sistema de gestão de recursos humanos e se alinham às competências organizacionais, à "missão" e aos valores da empresa. A educação corporativa se converte em instrumento eficaz de alinhamento entre o desenvolvimento dos talentos humanos e as estratégias empresariais. Essa preocupação socializadora transcende os muros das empresas. Verifica-se, nas empresas pesquisadas, o investimento em programas de qualificação profissional para o segmento mais jovem da população capixaba (programa trainee, aprendizes de nível médio e técnico, etc.). O perfil das novas gerações demanda novas formas de motiva- 
ção, uma evidência de que a socialização na empresa não se processa alheia às mudanças de valores e de comportamentos que ocorrem na sociedade, sobretudo entre as novas gerações.

Ainda no que se refere ao desempenho da função socializadora, a previsibilidade na reposição de pessoal garante a preservação da estabilidade das competências organizacionais. A organização do banco de talentos é uma arma contra a descontinuidade na reposição ou na ampliação no quadro de pessoal. Neste sentido, a empresa C conta com o programa Carreiras \& Sucessões, que é considerado, segundo os documentos institucionais, "o verdadeiro planejamento estratégico de recursos humanos", por meio do qual procura-se "conciliar as necessidades atuais e futuras da companhia" com o "potencial e perfil de competências de cada empregado". O recrutamento interno, visto como uma forma de "oferecer perspectivas de crescimento na carreira dos empregados que já estão na empresa" é realizado a partir de um Banco de Oportunidades, por meio do qual se procura identificar, no interior da empresa, os empregados capazes e dispostos a novos desafios. O recrutamento externo é utilizado quando não se dispõe internamente de funcionário com o perfil desejado, ou quando se pretende um perfil diferenciado ou mesmo a renovação do quadro funcional.

Apesar de persistir a referência à empregabilidade nos discursos sobre qualificação, são fortes as indicações de que ela não é a principal diretriz na orientação dos processos formativos. E, talvez, nunca o tenha sido de fato, sendo mais recurso retórico que legitimava as ações de treinamento no momento em que as empresas promoviam o enxugamento do quadro. Com o quadro funcional estabilizado, sobrepõe-se a preocupação de reter o pessoal em que se investiu, valorizando-se o desenvolvimento das carreiras e a sucessão interna.

Um dos desafios enfrentados pelas empresas é a competição acirrada entre elas pelo acesso aos recursos essenciais que são os indivíduos talentosos, qualificados e informados. Observa Marsden (2004) que a instabilidade dos mercados ocupacionais, sobretudo a escassez de determinadas qualificações, favorece práticas predatórias entre as empresas, desmotivando o investimento em formação.

A pesquisa realizada em 1.396 organizações, distribuídas em 60 países, apontou os fatores de "atração" e de "retenção" de profissionais talentosos 
como as questões mais críticas na gestão de pessoas. As empresas mais competitivas se destacam, sobretudo, pela capacidade de atrair e reter os talentoschave, os "profissionais que fazem diferença no desempenho da corporação" - um problema mais contundente no segmento dos executivos e técnicos do que entre os profissionais do setor operacional e administrativo. ${ }^{2}$

Esta constatação reforça as teses de que, para seletivos segmentos profissionais, as mudanças no mercado de trabalho têm sido promissoras. E mais: nestes segmentos é provável que a dependência da empresa em relação a eles tenha se elevado. No entanto, essas mesmas considerações alimentam outro paradoxo: se há indícios expressivos da valorização do trabalhador, da preocupação com a sua estabilização na empresa, também são visíveis as estratégias de racionalizar o investimento em formação tendo em vista a redução de custos e a minimização dos riscos da perda de profissionais qualificados para outras empresas.

Nesta linha de argumentação, o plano de autodesenvolvimento, uma das principais diretrizes da educação corporativa, parece estar mais relacionado com a estratégia racionalizadora de custos e riscos, do que com a empregabilidade. A pesquisa realizada pela FIA (Fundação Instituto de Administração) em 134 companhias brasileiras detectou que 52\% das empresas da amostra já tinham incorporado programas de autodesenvolvimento profissional. Por meio deste recurso, transfere-se ao empregado a responsabilidade, incluindo o ônus financeiro, pelo desenvolvimento de sua carreira profissional. Se, por um lado, tal postura pode indicar a ruptura com a visão paternalista de empresa, por outro, cabe indagar se a transferência da gerência da carreira aos empregados não abala a lealdade e o comprometimento que eles devotavam aos seus empregadores (Folha de São Paulo, 22/01/06).

Sem dúvida, este é apenas um ângulo do autodesenvolvimento. De fato, ele vai além da matriz de custos das empresas. $\mathrm{Na}$ empresa $\mathrm{C}$, a avaliação do desempenho e a definição do plano de desenvolvimento das competências dos empregados começam com a avaliação conjunta entre o empregado e seu chefe imediato, e, com base neste diagnóstico, definem-se os cursos. A noção de carreira é "ressignificada" pois, na visão da empresa, deixa de ser "um caminho rígido" e se torna uma "seqüência de posições e trabalhos realizados

2 “Caça aos talentos", Mundo Corporativo, n. 11, 1ำ trimestre de 2006, p. 24-37. 
pela pessoa", articulada de forma a "conciliar desenvolvimento pessoal com desenvolvimento organizacional”.

O discurso da autonomia está longe de qualquer voluntarismo e precisa ser contextualizado nos limites das demandas e objetivos da organização. Monitorado pela gerência, o processo de formação define metas alinhadas ao longo de toda a estrutura organizacional, nos níveis administrativo e operacional, e em sintonia com as diretrizes estratégicas da empresa.

\section{O destaque das competências técnicas}

Apesar da ênfase nas chamadas competências sociais, observada na literatura sobre formação profissional, as pistas são sugestivas de que, no setor industrial, os saberes e habilidades técnicas ainda são o coração do processo formativo, constituindo a base a que serão agregadas outras modalidades de competências. Ilustra esta constatação a preocupação em recrutar alunos do Senai e da Escola Técnica, e certificar profissionais, por meio da Associação Brasileira de Manutenção (Abraman), sobretudo nas funções de eletricista, mecânico, instrumentista e caldeireiro.

No entanto, a valorização da capacitação técnica não significa alimentar a ilusão do conhecimento prático sem base conceitual. $\mathrm{O}$ investimento no ensino formal é o caminho para desenvolver a base conceitual (capacidade analítica), para a mudança dos modelos mentais, condição indispensável para o manejo de equipamentos modernos. Nas três empresas, por meio de convênios com instituições de ensino, como o Senai, Sesi e o Cefet, foram capacitados jovens trabalhadores que concluíram o ensino fundamental, médio ou técnico, bem como a formação específica em manutenção e operação nas suas áreas de negócio. Também ilustra este destaque da capacitação técnica a avaliação de desempenho da empresa $\mathrm{C}$, fundada em três tipos de indicadores em ordem de importância: indicadores técnicos individuais, indicadores técnicos de equipe e indicadores comportamentais.

Portanto, na contramão do discurso dos consultores e de análises acadêmicas que tendem a ressaltar a importância das competências sociais, comportamentais em detrimento das técnicas, nas três empresas pesquisadas, a escolaridade, os saberes e as habilidades técnicas são critérios básicos para 
recrutamento e promoções internas. São peças decisivas no caminho para a excelência - o passaporte para o mercado, sobretudo o internacional.

\section{Qualificação, ideologia e ética do trabalho}

Por fim, cabe ressaltar que uma das vertentes sob a qual é possível compreender o atual discurso da qualificação profissional, ou mais especificamente da educação corporativa, reporta aos traços típicos da moldura clássica do industrialismo. Não é excessivo recordar que o triunfo da "civilização industrial", sob a égide das relações sociais capitalistas, como afirmam vários autores (entre eles: Weber, Perrot, Bendix e Thompson) exigiu uma nova ordem, uma nova racionalidade, uma nova visão de mundo, um alicerce valorativo que não fosse exclusivo de um segmento da sociedade mas, sim, compartilhado pela maioria, expressando a "cultura capitalista" e modelando um tipo específico de sociedade. Transcendia, portanto, à esfera das relações de mercado.

Boltanski e Chiapello (1999) retomam essa questão e a transformam em uma questão inerente ao capitalismo, e não exclusiva de sua fase de fundação. É perene a necessidade de uma base ideológica legitimadora das formas produtivas e organizativas - o espírito do capitalismo de cada época - apaziguando as inquietações suscitadas pelas indagações a respeito dos possíveis ganhos individuais em troca da adesão ao trabalho, ou mesmo justificando, em termos do bem comum, o sentido do engajamento na empresa capitalista. Trata-se, portanto, de questões que continuam demandando respostas atualizadas, em sintonia com o momento histórico-cultural - uma demonstração de que a organização da produção permanece dependente de uma estrutura de crenças, valores e representações que facilitem a adesão ao trabalho e a legitimidade das práticas e das relações sociais.

Observa-se a continuidade ou reatualização da dependência por parte da organização da produção de um "cosmo" capitalista, de razões morais, portanto dos processos socializadores desencadeados em diferentes esferas da vida social. E os processos de qualificação profissional e capacitação social são componentes deste esforço socializador. Desta forma, identifica-se a matriz teórica que sustenta o discurso a respeito do "investimento na formação de capital humano" como necessário para o desenvolvimento das nações, 
para a promoção social, para o combate à pobreza e, mais recentemente, o seu renascimento nas "doutrinas" da administração: os recursos humanos como a matéria nobre da empresa, as "jóias" da engrenagem empresarial (López-Ruiz, 2004), às quais devem ser canalizados investimentos, tanto em treinamento e qualificação quanto em proteção e segurança.

Essa matriz sustenta também o que muitos autores caracterizam como um tipo de welfare corporativo, delineando uma situação um tanto paradoxal: de um lado a postura de responsabilidade social das empresas, traduzida no investimento em formação e segurança de seus empregados, de outro, o apelo a que os trabalhadores assumam o gerenciamento da própria carreira. O plano de autodesenvolvimento como forma de desenvolvimento do capital humano, sobretudo do capital intelectual, expressa esta empreitada que demanda investimento planejado em ações e práticas de formação e aperfeiçoamento, e também a cumplicidade da família, uma vez que grande parte dessas atividades ocorrerão fora do horário de trabalho, encurtando o chamado "tempo livre".

Por este ângulo, retoma-se a matriz contratualista, fundada na relação entre proprietários que atuam no sentido de preservar, maximizar e desenvolver seus capitais. Os trabalhadores transformaram-se em uma modalidade de capitalistas, mas não pela via do partilhamento da propriedade das ações das empresas, e sim pela "aquisição de conhecimentos e de capacidades que possuem valor econômico" (López-Ruiz, 2004). Observa-se a ampliação da noção de capital, como ilustra a definição do capital cultural, constituído pelos conhecimentos e competências, os ativos específicos dos assalariados. Trata-se de uma definição abrangente que inclui os bens intelectuais do empregado ou dos gestores: conhecimentos, experiências, habilidades, expertise e as diversas capacidades manifestas ou potenciais (Klein, 1998).

Mas, sob o ângulo do interesse, como mencionado anteriormente, a dimensão contratual não contempla nem a complexidade das motivações humanas nem a complexidade da dinâmica organizacional. A idéia de empresa como espaço de encontro, de troca entre capitalistas, é por demais vinculada à racionalidade instrumental, e insuficiente para explicar a densidade de processos e práticas sociais pautados por outras lógicas. Mais uma vez, o recurso a Boltanski e Chiapello (1999) é instigante, pois, segundo os autores, o declínio do controle hierárquico nas organizações promove o retorno às relações 
pessoais e à confiança entre as pessoas, sendo a confiança cultivada em várias frentes, como fundamento de alianças estratégicas e afetivas: entre os membros de uma equipe, entre a empresa e seus empregados, e entre as instituições.

Os riscos de novas formas de dominação mais sutis e dissimuladas são grandes, tal como exaustivamente já foi apontado na crítica sociológica do capitalismo. Ao acionarem dispositivos como afetividade, senso moral, honra e capacidade de invenção que, por serem mais humanos, penetram mais profundamente na interioridade das pessoas, as novas estratégias de gestão tornam o engajamento mais completo, mais protegido da consciência crítica do sujeito.

\section{Referências}

ALPERSTEDT, C. As universidades corporativas no contexto do ensino superior. Tese de Doutorado, FEA/USP, 2001.

ANTONELLO, C. S. A metamorfose da aprendizagem organizacional: uma revisão crítica. In: RUAS, R.; ANTONELLO, C. S.; BOFF, L. H. (orgs.). Os novos horizontes da gestão: aprendizagem organizacional e competências. Porto Alegre: Bookman, 2005.

BOLTANSKI, L.; CHIAPELlO, E. Le Nouvel esprit du capitalisme. Paris: Gallimard, 1999.

BRANDÃO, G. R. A. Universidade corporativa e a gestão de recursos humanos: novas configurações para antigas funções? Um estudo na universidade corporativa do Banco do Brasil (UNI-BB). Belo Horizonte: Ufmg, 2004.

BRANDÃO, G. R. Gestão de pessoas e as universidades corporativas: dois lados da mesma moeda? RAE - Revista de Administração de Empresa. São Paulo, v. 46, n. 2, abr.-jun. 2006, p. 22-33.

CAPPELLIN, P.; GIULIANI, G. M. A racionalidade, a cultura e o espírito empresarial. Sociedade e Estado, Brasília, v. 17, n. 1, jan.-jun. 2002, p. 123-152.

DENGO, N. Universidades corporativas: modismo ou inovação? Dissertação de Mestrado. Programa de Pós-graduação em Administração/Ufrgs, Porto Alegre, 2001.

DRUCKER, P. F. Sociedade pós-capitalista. São Paulo: Pioneira, 1993.

DUBAR, C. A sociologia do trabalho frente à qualificação e à competência. Educação e Sociedade. São Paulo, v. 19, n. 64, 1998, p. 87-103.

DUMONT, L. Homo Hierarchicus - o sistema de casta e suas implicações. São Paulo: Edusp, 1992. 
DURKHEIM, E. Da divisão do trabalho social. 2. ed. São Paulo: Martins Fontes, 1999.

EBOLI, M. Educação corporativa no Brasil: mitos e verdades, São Paulo: Editora Gente, 2004.

. O papel das lideranças no êxito de um sistema de educação corporativa. RAE - Revista de Administração de Empresa. São Paulo, v. 45, n. 5, p. 118-122, out.-dez. 2005.

FARTES, V. L. B. Trabalhando e aprendendo: adquirindo qualificação em uma indústria de refino de petróleo. Educação e Sociedade, Campinas, v. 23, n. 78, 2002.

GARAVAN, T. N.; O'CINNEIDE. B. Entrepreneurship education and training programmes: a review and evaluation - part 1. Journal of European Industrial Training, v. 18, n. 8, 1994, p. 3-12.

GRAMSCI, A. Americanismo e fordismo, em Maquiavel, a política e o estado moderno. Rio de Janeiro: Civilização Brasileira, 1984.

HABERMAS, J. Técnica e ciência como ideologia. Lisboa: Setenta, 1987.

HIROSE, L. M. La dimensión cultural de la organización. Elementos para un debate en América Latina. In: TOLEDO, Enrique de la Garza (Coord.). Tratado latinoamericano de sociología del trabajo. México: El Colégio de México/Flacso/Unam/Fondo de Cultura Económica, 2000.

HYMAN, R. Europeização ou erosão das relações laborais? In: ESTANQUE, E. et al. (Org.). Mudanças no trabalho e ação sindical: Brasil e Portugal no contexto da transnacionalização. São Paulo: Cortez, 2005.

. Sistemas nacionais de relações industriais e os desafios da transnacionalização: um balanço bibliográfico. Revista Latinoamericana de Estudios del Trabajo, São Paulo, Alast, ano 5, n. 9, p. 115-142, 1999.

KANTER, E. M. When a thousand flowers bloom. In: SWEDBERG, R. (Ed.). Entrepreneurship: the social science view. Oxford: Oxford University Press, 2000.

KLEIN, D. A gestão estratégica do capital intelectual: recursos para a economia baseada em conhecimento. Rio de Janeiro: Qualitymark, 1998.

LÓPEZ-RUIZ, O. J. O 'ethos' dos executivos das transnacionais e o espírito do capitalismo. Tese de Doutorado. Departamento de Sociologia do Ifch-Unicamp, 2004.

MARSDEN, D. Sistemas de emprego, estratégias de gestão e instituições do trabalho. Tempo Social. Revista de Sociologia da USP, v. 16, n. 2, p. 225-255, nov. 2004.

MEISTER, J. Educação corporativa: a gestão do capital intelectual através das universidades corporativas. São Paulo: Makron Books, 1999.

OFFE, C. O capitalismo desorganizado. São Paulo: Brasiliense, 1976. 
PAGÈS et al. O poder das organizações: a dominação das multinacionais sobre os indivíduos. São Paulo: Atlas, 1987.

POLANYI, K. A grande transformação: as origens de nossa época. Rio de Janeiro: Campus, 1980.

RAUD-MATTEDI, C. A construção social do mercado em Durkheim e Weber: análise do papel das instituições na sociologia econômica clássica. Revista Brasileira de Ciências Sociais. São Paulo, v. 20, n. 57, 2005.

REYNAUD, J. D. Le management par les compétenses: un essai d'analyse. Sociologie du Travail, 43, 2001, p. 7-30.

RUAS, R. Gestão por competências: uma contribuição à estratégia das organizações. In: RUAS, R.; ANTONELLO, C. S.; BOFF, L. H. (orgs.). Os novos horizontes da gestão: aprendizagem organizacional e competências. Porto Alegre: Bookman, 2005.

SAINSAULIEU, R. L'identité au travail. Paris: Presse de la Fondation Nacionale de Sciences Politiques, 1977.

SANTOS, G. V. Novas formas de gestão da produção e do trabalho na indústria capixaba de celulose. 1999. Dissertação de Mestrado em Política Científica e Tecnológica, IGE/Unicamp, Campinas, 1999.

SEGRESTIN, D. L'entreprise à l'épreuve des normes de marché. Les paradoxes des nouveaux standards de gestion dans l'industrie. Revue Française de Sociologie, v. 38, p. 553-585, 1997.

SOUZA, E. C. L. Empreendedorismo: da gênese à contemporaneidade. In: SOUZA, E. C. L.; GUIMARÃES, T. A. (orgs.). Empreeendedorismo além do plano de negócios. São Paulo: Atlas, 2005.

SPURK, J. Une critique de la sociologie de l'entreprise: l'hétéronomie productive de l'entreprise. Paris/Montréal: L'Harmattan, 1998.

STEWART, T. A riqueza do conhecimento: o capital intelectual e a organização do século XXI. Rio de Janeiro: Campus, 2002.

SUPERVIELLE, M.; QUIÑONES, M. La incorporación del trabajador al trabajo: gestión y auto-gestión de los conocimientos en la sociedad de controle (la perspectiva de la sociología del trabajo). In: Revista Latinoamericana de Estudios del Trabajo, año 8, n. 16, 2003.

VILLAVICENCIO, D. Economia y Sociologia: história reciente de uma relación conflitiva, descontinua y recurrente. In: TOLEDO, Enrique de la Garza (Coord.). Tratado Latinoamericano de Sociología del Trabajo. México: El Colégio de México/Flacso/Unam/Fondo de Cultura Económica, 2000.

WEBER, M. Economia e sociedade: fundamentos da sociologia compreensiva. Brasília: Editora Universidade de Brasília, 1991. v. 1.

A ética protestante e o espírito do capitalismo. São Paulo: Pioneira, 1967. 